\title{
The fear of falls in the caregivers of institutionalized elders
}

How to cite this article: Baixinho CL, Dixe MA, Henriques MA Marques-Vieira C, Sousa L. The fear of falls in the caregivers of institutionalized elders. Rev Gaúcha Enferm. 2021;42:e20200258. doi: https://doi. org/10.1590/1983-1447.2021.20200258 a Escola Superior de Enfermagem de Lisboa (ESEL), Lisboa, Portugal.

b Politécnico de Leiria, Escola Superior de Saúde, Center for Innovative Care and Health Technology. Leiria, Portugal.

c Politéenico de Leiria. Leiria, Portugal.

¿ Universidade Católica Portuguesa (UCP), Instituto de Ciências da Saúde, Centro de Investigação Interdisciplinar em Saúde. Lisboa, Portugal.

Eniversidade de Évora, Comprehensive Health Research Centre. Évora, Portugal.

\section{Cristina Lavareda Baixinho ${ }^{a, b}$ Maria dos Anjos Dixe ${ }^{b, c}$ Maria Adriana Henriques ${ }^{a, b}$ Cristina Marques-Vieira ${ }^{d}$ Luis Sousa ${ }^{e}$}

\section{ABSTRACT}

Aims: To understand how the fear of falls emerges and manifests itself in caregivers of institutionalized elders.

Method: It is a qualitative study, based on the Grounded Theory and carried out with 24 informal caregivers, 5 nurses, 2 physicians and 2 directors of two Portuguese nursing homes. Data collection took place through interviews, participant observation, and documentation analysis, between October 2016 and January 2018. Data was collected and analyzed simultaneously, following the stages of open, axial, and selective coding.

Results: The comparative analysis of the findings identified the conceptual category "Fear of falls in the caregivers of institutionalized elders". The main category is associated with the categories: maintaining safety, hidden fear of falls, the perceived self-efficacy in the prevention of falls, falls and interpersonal relations, previous experiences, and team support.

Conclusions: The fear has an influence on the self-efficacy perceived in the prevention of falls; the quality of the teamwork, in turn, is affected by previous negative experiences and by the support of the team.

Keywords: Accidental falls. Aged. Homes for the aged. Fear. Caregivers. Institutionalization.

\section{RESUMO}

Objetivo: Este estudo teve por objetivo compreender como surge e se manifesta o medo de queda nos cuidadores de idosos institucionalizados.

Método: Estudo Qualitativo suportado pela Grounded Theory realizado com 24 cuidadores informais, 5 enfermeiros, 2 médicos e 2 diretores de duas Instituições de Longa Permanência para Idosos Portuguesas. A colheita dos achados foi feita com entrevistas, observação participante e análise da documentação, entre outubro de 2016 e janeiro de 2018. Os dados foram coletados e analisados simultaneamente, seguindo as etapas da codificação aberta, axial e seletiva.

Resultados: A análise comparativa dos achados identificou a categoria conceitual: Medo de queda nos cuidadores de idosos institucionalizados, com as categorias associadas: manter a segurança, medo oculto de queda, autoeficácia percebida na prevenção e quedas, a queda e as relações interpessoais, experiências anteriores e suporte da equipe.

Conclusões: 0 medo afeta a autoeficácia percebida na prevenção de quedas; a qualidade de trabalho em equipa e é influenciado pelas experiências anteriores negativas e pelo suporte da equipa.

Palavras-chave: Acidentes por quedas. Idoso. Instituições de longa permanência para idosos. Medo. Cuidadores. Institucionalização.

\section{RESUMEN}

Objetivo: Este estudio tuvo como objetivo comprender cómo surge y se manifiesta el miedo a caerse en los cuidadores de ancianos institucionalizados.

Método: Estudio cualitativo apoyado por Grounded Theory realizado con 24 cuidadores informales, 5 enfermeras, 2 médicos y 2 directores de dos hogares de ancianos portugueses. Los hallazgos fueron recopilados con entrevistas, observación participante y análisis de la documentación, entre octubre de 2016 y enero de 2018. Los datos se recopilaron y analizaron simultáneamente, siguiendo las etapas de codificación abierta, axial y selectiva.

Resultados: El análisis comparativo de los hallazgos identificó la categoría conceptual: el miedo a caer en los cuidadores de ancianos institucionalizados, con categorías asociadas: mantenimiento de la seguridad, miedo oculto a las caídas, autoeficacia percibida en prevención y caídas, caídas y relaciones interpersonales, experiencias previas y apoyo al equipo.

Conclusiones: El miedo afecta la autoeficacia percibida en la prevención de caídas; La calidad del trabajo en equipo está influenciada por experiencias negativas previas y el apoyo del equipo.

Palabras clave: Accidentes por caídas. Anciano. Hogares para ancianos. Miedo. Cuidadores. Institucionalización. 


\section{口INTRODUCTION}

Falls are a serious public health problem. They are the third cause of chronic disability and are associated with declines in functionality, high morbidity and mortality, increased dependency, and higher costs with the treatment of secondary lesions $s^{(1-5)}$. The increase in the mean life expectancy means that both falls and lesions are seen as a "growth area", since their prevalence will increase, with estimates that suggest it will have doubled in 2040(2-3,6).

Nearly $30 \%$ of elders fall at least once a year. The probability of their falling again varies from 60 to $70 \%^{(1-2)}$, and one in every five falls requires medical attention ${ }^{(1,3)}$. In nursing homes, the prevalence is higher, due to contributing factors such as the high dependency levels of the elders, their cognitive decline, multiple pathologies, polymedication, differences in the environment of these institutions, and to the unsafe practices of elders and workers ${ }^{(4)}$, among others.

This situation is worsened by the fact that most falls take place in the first days after institutionalization ${ }^{(4)}$, which in turn leads to an increased risk of falls in the following months. The fall and the cumulative effect of the fear of falling, of post-fall syndrome, and of secondary lesions, in a society in which the number of elders is increasing exponentially, leads to the potential risk of an epidemic and to a high consumption of health resources ${ }^{(7)}$.

The fear of falling is not only a consequence of the fall, but also increases the risk of this type of accident, since losing trust in daily life activities and an increased physical inactivity lead to the loss of muscle strength and gait quality, predisposing the elder to fall again ${ }^{(2,7-8)}$. In addition, in nursing homes, after a first fall, elders diminish their activity due to the fear of falling again, or restrictions to the activity are imposed on them, leading to dependency $y^{(2,8-9)}$.

A study carried out in the community shows that the recurring falls are the main factors for the fear of falling among elders who live in their own home ${ }^{(9)}$. Those who fell twice were more afraid than those who never did and than those who only fell once ${ }^{(9)}$. They also mention that those whose fall had complications (fractures, injuries, or severe lesions), women, and elders with worse health state self-evaluation, as well as those above 70 years of age, are more susceptible to the fear ${ }^{(9)}$.

A study carried out in a nursing home found that an increase in the Fall Efficacy Scale (FES-I) score indicates lack of self-confidence in the safe performance of daily life activities, and is associated with the number of falls in the previous year and with a diminution of balance ${ }^{(10)}$.

It is important to highlight that the phobic fear of a (new) fall is a factor that can be modified through preventive interventions to control both the falls and the fear of falling. However, in nursing homes, the caregivers assume that the fear of falling the elder has should condition their decisions in the care, taking overprotective measures that lead to restrictions in the activities and limits the participation of the elder in social situations ${ }^{(4,7)}$.

A literature review showed that investigations on the fear of elders have been more successful in the community than in nursing homes, where the presence of residents and other professionals may have an influence in the fear of falling ${ }^{(8)}$. It also showed that studies have not been exploring the influence of the fear that the elder will fall on the practices of caregivers and on the safety interventions implemented. We corroborate the statements according to which the implications of ptophobia go beyond the barrier of care in health, of clinical practices and of epidemiology, and as a result, society must considered it from a perspective that takes its particularities into account ${ }^{(9)}$.

Considering the above the guiding question of this research was "How does fear of falling influence caregivers of institutionalized elderly?". This study aimed at understanding how the fear of falls emerges and manifests itself in caregivers of institutionalized elders.

\section{METHOD}

This is a qualitative study based on the Grounded Theory, whose use is recommended when the phenomenon has not yet been explored or there are few scientific works on the subject. It enables the study to explain the phenomenon through, simultaneously, an understanding of the action and of the context ${ }^{(11)}$.

The study was carried out in two nursing homes, in the Lisbon and Tagus valley region, in Portugal, that gave their consent, from October 2016 to January 2018. The institutions have similar organizational characteristics. One has 88 institutionalized elderly and a team of 49 professionals, while the other has 120 elderly and 63 professionals. Both function as permanent residences, home support, and day care centers. In each institution, the technical director helped to identify the caregivers and health professionals who provide care, exclusively, to elderly residents in the nursing home. All professionals were informed of the presence of an investigator and the purpose of the study.

The participants were 24 informal caregivers, 5 nurses, 2 physicians, and the 2 directors of the institutions involved, arranged in two sample groups. In the first sample group 8 caregivers and 2 nurses were included. These informants met the criteria defined for the participants' inclusion: caregivers who worked in direct care to the elder and agreed of their 
own free will to participate in the study. Access to these informants was provided by the technical director of the institution that presented the researcher to the participants and allowed access to the context.

Based on the data collected from the first sample group, the following hypothesis was elaborated: the fear of falling influences the practices of the teams in the provision of care to the institutionalized elderly. The composition of the second sample group allowed us to explore the relationship between the fear of falling and the decision-making of the different professionals. This group is constituted by 16 caregivers, 3 nurses, 2 physicians and 2 directors.

The data collection was completed with theoretical saturation of data ${ }^{(11)}$, so that this investigation could clarify how the fear that the elder falls presents itself in the caregivers, what influences this feeling, and how it conditions the offering of care to institutionalized elders who are under the risk of falling and/or fell in the past.

The techniques used to acquire data were the participant observation in the contexts where the study took place, the semistructured interviews to the different professionals, the consultation to clinical procedures and to the documents produced by professionals about the fall. The interviews would start with the guiding question:"Do you believe that the team is afraid that the elders may fall in the institution?", and were later guided towards the questions a) "How do you think that fear influences the care for the elderly?"; b) "After an elderly person falls what measures must the team take to prevent another fall?"; c) "How does the team react when an elderly person falls?". The interviews were recorded and transcribed.

The varied respondents generated a better understanding of the process and made it possible to understand the relation between concepts, enriching the interpretation and guiding the emergence of new questions to reveal the complexity of relations established between sources and concepts, as well as the emergence of categories, their properties and dimensions, according to the information's found to be necessary as the research was developed ${ }^{(11)}$.

The observation in the "natural context" of the workers and of their interactions with the elders was important to accompany the performance of different activities in the morning and afternoon shifts. As a result, it became possible to understand the organization of care and the choices made as a result of the phenomenon under study. The findings from the interviews guided the observations ${ }^{(11)}$.

After the collection and analysis of the data obtained from the first sample group, through interviews and observation, it was necessary to consult the clinical processes for analysis of the records made on falls and their written communication among the team.
Data was collected and analysed simultaneously ${ }^{(11)}$, following the stages of corpus coding (open, axial, and selective coding) until theoretical propositions were formulated as a result of the analysis of the relations between the categories. Data analysis was based on a process of constant comparison $^{(11)}$. From the successive stages of analysis emerged concepts and hypotheses or propositions to be deepened and/ or validated at times of subsequent collection. During this process the researcher retired field notes with the description of the observation, with reference to the provision of care to the elderly, organization of the physical environment of the elderly, decisions on care related to the previous occurrence of fall, among others. Reflective/interrogative and interpretative notes of the analysed and perceived, in addition to observation and listening were made. These notes were important for the course of research and for understanding the phenomenon.

During the analysis process, the findings, the analysis and emerging categories, were questioned. The findings were returned to the participants, to focus the process on the context.

To guarantee anonymity, a code was assigned to each participant, with reference to the professional category (informal caregivers (IC), nurses (N), physicians (P), and the 2 directors (D)) and a number for the interview (I) or observation (O).

This study was approved by the Ethics Commission (Ref. ICS/268/2012). The nursing homes involved gave their authorization. Participants were asked for their free and informed consent. The anonymity and confidentiality of data was guaranteed.

\section{RESULTS}

The comparative analysis of the findings led to the identification of the conceptual category: fear of falls in the caregivers of institutionalized elders, which allowed an understanding that the fear is present in the professionals of the institutions and influences the organizational culture and the organization of the care to the elders who live in the institution. The preoccupation of professionals is keeping the elders safe, but their choice of preventive measures against falls is influenced by the hidden fear of falls. The fear is "fed", in these workers, by the perception that the risk of falls is real, by a sense of the consequences this type of accident has on the life of an elder (in the short, medium, and long terms), by the fear of the impact of the fall of the elder in the relations within the teams and in the relations with the family of the elder. The fear has an influence on the self-efficacy perceived in the prevention of falls; the quality of the teamwork, in turn, is affected by previous negative experiences and by the support of the team. 


\section{Maintaining safety}

The safety of institutionalized elderly people goes beyond the prevention of falls. However, this is undoubtedly an adverse event which must be prioritized, and caregivers, due to the skills and characteristics of their performance, carry out decisive clinical interventions. They are often faced with decision making and execution; also, what they think, say and do has a definite influence on the safety of the institutionalized elderly.

The caregivers assume that the social responsibility of the nursing homes and their individual responsibilities are with the offering of care to a vulnerable group of the population. These risks include not only health-disease transitions, but also the transcription for a situation of institutionalization.

The need to answer to this social and individual demand implies not harming another:

our objective is being caring and keeping them safe, this is their new home (...) nothing can happen here because the institution is accountable, that is, we are (...) the greatest problem is when they fall (I - IC23), it isn't common to talk about that with the workers, but when they communicate that a fall took place, they are afraid of being reprimanded (I - P2).

This concern with safety manifests itself in the different moments of interaction between the team. In their change of shift, they often speak about interventions to maintain the safety of the elderly, especially when a moderate or severe injury occurs. In one of the interactions during the shift change one of the caregivers stated:

I Failed! I thought she was safely in the chair in the room because there's always someone around, but still, Ms. M. got up and fell (O74).

With regards to maintaining the safety of the elderly, both caregivers and health professionals express increased concern with security of those who are afraid of falling, those who present greater fragility, dependence, or cognitive decline.

it is always bad when a fall occurs, but it's more worrisome in those with cognitive changes, because the family expects us to take care of them, since they are no longer in a position to do so (...) the director also 'slaps our wrists' more when the fall occurs with a demented elderly, she immediately says that we cannot justify the fall with the elderly's behavior, because they do not know what they are doing (I-IC 3).

The fear of falling arises from the perception of the existing danger, which threatens the safety of the elderly, and all actors consider that its occurrence has serious consequences for their autonomy and independence. The fear of caregivers is caused by the perception of the consequences of this accident.

\section{Hidden fear of falls}

The fear of falls is present in the elders and in the workers. In the moments of interaction and in the analysis of the records, there is no information on whether the elder is afraid of falling. Not even the descriptions of individual risk factors make any reference to it. In the interviews, the fear is reported and it becomes clear that the professionals know that the elder is afraid of falling. Even elders who never fell become afraid after the fall of another elder who lives in the institution, and workers themselves are afraid that an elder would fall in their shift.

The fear is not discussed within the teams, but it is present, associated to the perception of a danger, of a threat to the safety and integrity of the elder. All participants consider that this situation has severe consequences for the autonomy and independence of the elders:

we all have a sense that a fall and a fracture lead to other complications, that is why no one likes when it happens in their shifts, but sometimes the fall is not immediately bothersome, we see them as situations that increase dependency (I-D1).

Falls are followed by feelings of guilt, by the fear of having failed in their prevention, but essentially, because one feels afraid that this failure in safety is one's own fault, and that it would lead to lesions:

elders fall, they already have many issues, we all know that, but it seems that the fault is ours, even when no one is to blame (I - IC1).

After a fall during their shift, workers experience contradictory feelings. The occurrence of previous falls with injury appears to be the major factor for the discussion and manifestation of the fear of another fall, but there is no single determining cause for the fear of the caregiver. On the other hand: there are multiple individual causes involving 
the elder, the worker, the organization, in addition to legal causes that contribute towards this process.

\section{The perceived self-efficacy in the prevention of falls}

The findings make it possible to understand that the fear of the caregivers has a cognitive component, related to the perception of the fear of the elder himself, to beliefs associated to accidents, to previous experiences and to the notion of self-efficacy and control. It also has a behavioral component, which impels one to replace the elder in carrying out daily life activities (DLA), which is justified with the idea of protection and a paternalistic discourse:

when someone falls is because they have problems associated to their age and their disease, that's al ways what it is, but if we hadn't let them do that by themselves they might not have fallen (I - CF17).

The perceived self-efficacy is influenced by the notion of competence based on the therapeutic relation and the maintenance of the elder in safety. Some workers make a point of stating that in their shifts there are less falls than in others, and, from their perspective, the lower prevalence is a consequence of their competence in the surveillance of the elder and in performing, for the elder, DLA. They avoid falls from the elders, for example, by preventing them from walking around in the institution, to prevent them from slipping:

this team is lucky, it is uncommon for many elders to fall in our shift (I - IC21).

In moments of interaction between the health professionals and the caregivers, this perceived self-efficacy is often manifested by the way questions are asked, not to clarify the action, but rather to confirm that this it was well done. The questions emerge as: "I did this because I considered the best option, did I do well?" (O - IC- 128).

The notion of competence in the prevention of falls is based not on the effective knowledge about the interventions that prevent episodes, but on a set of beliefs about risk factors, their interaction, how to prevent them and by the association of non-occurrence of falls with being competent.

\section{Falls and interpersonal relations}

From an organizational point of view, the notion of the I in the team, coupled with power relations that, however, are not explicit in the discourse of professionals, are forces that determine, informally and surreptitiously, the perpetuation of fear and guilt.

A worker who was new in one of the institutions discuss this issue by as such:

I'm here for a little time, they are still seeing how I work, the colleagues always have their eye on me, no elder fell under my watch, but if they do it soon casts you under a bad light (I - IC17).

One of the nurses observes that:

all workers have been in a situation in which an elder fell in their work shift, if it happens in a team where people like each other no one will reprimand, but if the worker is someone who isn't well accepted by the team or if people in the team have a bad relationship, there's a lot of talk and questioning for days (I - N5).

On the other hand, the fear that the family will pursue legal action for negligence with legal consequences that can even lead to job losses, are preponderant factors that increase the fear:

it is increasingly difficult to notify a family about a fall, they immediately question who was responsible for it (I-N4).

It is evident in moments of interaction, in team meetings and in interviews that the occurrence of falls, especially with injuries, influences the relation between different caregivers, and their acceptance in the team and the interpersonal relationships, with the risk of someone being blamed for the accident.

\section{Previous experiences}

The self-efficacy noticed in the prevention of falls and the control noticed on the performance of DLAs are influenced by the previous experiences of the workers.

Their previous experience, especially the negative ones, influence the fear they feel and the decisions they make on the care to be offered:

since Mr. J. passed away after a fall in a night that was my shift, I have been more careful, I wasn't to blame, but the situation really traumatized me, since then I am increasingly afraid that someone will fall on the stairs, I don't even let them go there (I - IC21) [Mr. J. suffered a traumatic brain injury after falling the stairs and passed away 12 hours later, in the hospital]. 
The previous experience of a fall also influences the communication with the elders on the subject of risk factors and preventive measures. Their previous falls with lesions emerge in the discourse of the caregivers, as do their professional experience with events that led to severe lesions:

when someone falls I always tell them to be careful (I ICO2); if they fall in the bathroom, with me, they'll never go back there alone (I - IC11).

After the occurrence of a fall with injury, the caregivers reinforce the surveillance of the elder who fell. The observation of the practices confirms what was said in the interviews, several warnings are made to the elder who fell to keep sitting in the chair and avoid walking or going to the bathroom alone (02, O17, O 29, O51, 092).

\section{Team support}

The support from the teams is important in the management of fear of falling and in the support to professionals when falls take place.

We always talk with the workers about the falls, we demand preventive measures, but we give support when they are worried about what happened (1 - D2).

The guidance and the collaborative work with the health team makes it possible to improve the workers'formation in the context of the work itself, since it enables the understanding that the falls have multi-factorial causes, which makes it difficult to implement preventive measures:

our physicians and nurses explain what we should do (...) when the elder falls they tell us and say what should be done after that to prevent further falls (I - IC18)

in the other institution where / worked whenever someone fell the doctor said that it was our fault for not being careful ... when someone fell we only communicated when there were wounds, here it is different we can communicate the falls and doctors and nurses explain to us what we should do ... this decreases the fear of talking to them and helps us learn what to do (I - IC 27).

One of the nurses observed that

in the institution we have several teams of caregivers, who guarantee the safety of the different units of the nursing home, and there are differences between them even in the communication of falls. In teams with greater relationship difficulties, only falls with injuries are reported to the health professionals,' caregivers tend to omit those that do not result in injury. In the team with best relationship, they worked together for severalyears and trust each other completely, so communication is natural within the team and no one is lectured (I - N1).

The power relations in the team, despite not being explicit in the discourse of the professionals, are decisive, in an informal and discrete way, for the perpetuation of fear and guilt.

\section{DISCUSSION}

The results found in this research make it possible to understand that the fear of falls is present in the caregivers of institutionalized elders and influences the provision of care and the interpersonal relations among all members of the team, including the elders and their families.

The fear of falling in elders has been associated to the falls and to their recurrence ${ }^{(9-10)}$. The fear is present, but it is not common for professionals to manifest it. A research with caregivers in the community also found a reluctance of caregivers to talk about this subject, giving their low educational level as a justification for it ${ }^{(12)}$. This fear may be more worrying among caregivers who are relatives of the elders than in the elders themselves ${ }^{(13)}$.

The fear of the caretaker influences their provision of care. When the caregivers experienced previous situations of fall with serious lesions in their working hours, the psychological trauma, the guilt and the fear of consequences leads to overprotective behavior, which can condition the autonomy and the independence of the elder in carrying out DLAs. Although moved by the intention of offering the best care possible, considering the particularities of each elder, the fear that the elder may fall predominates, and, as a result, interventions are implemented. They are said to be preventive, but do not allow the elder to carry out simple routine activities ${ }^{(12)}$.

The dynamics of the teams are influenced by the fear of recrimination and discrimination towards the workers in whose shifts a fall took place. That implies in changes in interpersonal and professional relations, increasing the pressure over the elder so that they remain safe ${ }^{(4)}$. Even the elderly avoid communicating the episodes of falls that are not witnessed and lead to no injuries, for fear of restrictions to their activity and of losing autonomy ${ }^{(4,7-8)}$.

A research carried out with elders who live in the community found that fear, in addition to having a high impact in the lives of elders, changes family dynamics ${ }^{(14)}$. Its participants were elders who had changes in their balance and their caregivers, who were relatives of the elders and were 
afraid of falls due to the alterations in balance and replace the elder, increasing their dependency, which is clearly translated into limitations in the activities of the caregivers and into restrictions for their social participation ${ }^{(4,7,9,14)}$. These actions lead to dependence ${ }^{(12,14)}$, and make it impossible for the elder to have autonomy and make them submissive, preventing them from enjoying pleasures of life such as a simple walk within their own house, or taking a bath by themselves ${ }^{(12)}$.

In nursing homes, the fear of falls felt by the caregivers, is predictive of the use of physical mobility restrictions. In turn, the use of physical restrictions predicts the future functional capacities of residents who have dementia or had previous falls with serious lesions ${ }^{(15)}$. These results reiterate findings regarding the promotion of the limitation of activities and the restrictions of social participations, which are understood as ways to keep the elder safe and prevent accidents.

The limitations of certain activities and the replacement of self-care promote immobility, leading to musculoskeletal alterations that make falls more likely ${ }^{(12,15-17)}$. Both attitudes (limitations and restrictions) are justified by the fear of further falls, since they are considered, by the participants, protective actions, and lead to more grave results when the person is in cognitive decline ${ }^{(4,18)}$.

Despite the impact of fear on quality of life and on the risk of a new fall, the assessment of the risk of falling is still centered around the biomedical model, with a greater appreciation for the physical risk factors ${ }^{(4)}$. This approach led to some advances, but it does not encompass all the complexity of fall events and their reporting ${ }^{(1,4,8,18)}$. In the numerous researches about the theme, studies on the bio-physiological risk factors predominate, to the detriment of the exploration of behavioral and environmental risks. Simultaneously, it can be noted that preventive measures are not always associated with the risks identified ${ }^{(1,4,10)}$.

In a society based on aging and on an increased number of people with functional and cognitive limitations, with a growth in the institutions that are used to answer the needs of the population, it is possible to see how the fear of falls influences the functioning of the elder ${ }^{(10,14-16)}$. The fear the elder feels is not the only factor to be considered, the fear felt by the professionals also must be taken into account, since their verbal guidance and their behavior with regards to protecting the elder is exactly what will lead elders to be physically and cognitively passive(15).

The repercussion of this phenomenon in the life of the elder and in the institution is a challenge in different domains, such as, for instance, in the evaluation of the risk of falling ${ }^{(19)}$, in the prevention against limiting activities, in the self-efficacy perceived, in the global health evaluation, in the quality of life $^{(4,16)}$ and in the formation of the teams itself ${ }^{(18,20)}$. The big challenge is that the assessment of the risk of falling should be multidimensional with an emphasis on psychological and behavioral risk factors instead of an assessment centered on biophysiological risk factors ${ }^{(1,5,7-10)}$.

The participants recognize the support and formation of the teams as central features to control their fear and improve the offering of care to the elder in risk of falling or who has previously fallen. We concede that the caregivers manage to carry out preventive actions, which are essentially related to extrinsic factors ${ }^{(18)}$ and are not based on knowledge, but on their own beliefs on what is efficient and on their daily life experiences ${ }^{(12)}$. However, they need to have knowledge on the type of care that is efficient to prevent falls, through a systematized approach of intervention in the teams, which should be led by a professional with the adequate formation to occupy this role ${ }^{(12,20)}$.

For some authors the high prevalence of falls justifies coordination among multiprofessional health teams at all levels of care, aiming at detecting the elderly who are at risk of falling or have a previous history of falls $s^{(5,20)}$. The 'fall leader', has a major role in promoting effective communication, developing new policies, forming and training the team ${ }^{(20)}$.

The intervention in the team must anticipate the issues and be based on an organizational culture of safety, adequate to the specificities of the geriatric population and to the context of nursing homes ${ }^{(8,12,20)}$. Unfortunately, the maintenance of a punitive culture in the face of a fall makes it difficult to accept and solve the problem, but it also makes the occurrence of these accidents an experience riddled with guilt on the part of the professionals ${ }^{(18-20)}$.

The high prevalence, the multifactorial nature of the risk in the genesis of the falls ${ }^{(20)}$, its consequences, and the complexity of preventive measures justify that, if other studies go in-depth in the relations between the fear of fall of caregivers, the risk, the prevalence, the lesions, and the practices of prevention.

The relation between self-efficacy and previous experiences, despite being an important finding in this study, was not entirely clarified in this study. Further studies should explore it to better understand how previous experiences, self-efficacy in falls and control over DLAs explain the role of the fear of falling in caregivers, and affect the decisions made by them in the provision of care to the elders.

\section{finAL CONSIDERATIONS}

The findings of this study make it possible to understand the fear of falls in caregivers of institutional elders. The fear is present. It is not addressed, but the workers are aware that the fall is a real danger, that is, an imminent danger that is difficult to control. 
The fear has a cognitive component, related to the perceptions of the elders themselves, their beliefs, previous experiences, and to the notion of self-efficacy and control; it also has a behavioral component that impels the caregiver to replace the elder in the performance of daily life activities, who use, to do so, the idea of protection and a paternalistic discourse.

The preoccupation of professionals is keeping the elders safe, but their choice of preventive measures against falls is influenced by the hidden fear of falls. The fear is "fed", in these workers, by the perception that the risk of falls is real, by a sense of the consequences this type of accident has on the life of an elder, by the fear that the fall may influence relations within the teams and the relations with the family of the elder. The fear has an influence on the self-efficacy perceived in the prevention of falls; the quality of the teamwork, in turn, is affected by previous negative experiences and by the support of the team.

The preoccupation with this accident is constant, but the teams do not always communicate and work together to evaluate the risks and associate the adequate preventive measures. The option chosen ends up being the restriction of the activities and the limitation of social participation, with consequences for the independence and autonomy of the elders.

This fear wearies the teams, impacting in interpersonal relations in their personal and professional marketing, since it is experienced in association with feelings of guilt when the fall happens and results in serious lesions.

The limitations of this study are associated with the nature of the method. The results allowed for an understanding of the phenomenon only in the contexts in which it was studied. The theoretical sample is not representative of the entire universe of nursing home professionals. The choice of institutions, the type of organization, the physical structure, and the formation of professionals may have influenced in the analysis of reality. Despite these limitations, the results allow for an understanding of fear in caregivers and the introduction of measures for its control and can contribute to the prevention of falls by identifying the fear in caregivers and their influence on the overprotection of the elderly. It also points to the need to improve communication between the team, the elderly and the family.

For the clinic, nurses must lead fall prevention programs in nursing homes that include the control of the fear of falls in caregivers, due to the potential impact they can have on the functionality of the elderly and in transforming this culture of punishment into a culture of safety, based on the analysis of situations and on a timely control of risks. Future investigations should determine how fear influences the provision of care to the elderly.

\section{REFERENCES}

1. Oliveira T, Baixinho CL, Henriques, MA. Prevention of falls - interventions in the home visits to the elderly: scoping review. IJOCS. 2018;12(1):e1000134. doi: https://doi.org/10.4172/Clinical-Skills.1000134

2. Dyer SM, Crotty M, Fairhall N, Magaziner J, Beaupre LA, Cameron, ID. A critical review of the long-term disability outcomes following hip fracture. BMC Geriatr. 2016;16:158. doi: https://doi.org/10.1186/s12877-016-0332-0

3. Wendt K, Heim D, Josten C, Kdolsky R, Oestern HJ, Palm H, etal. Recommendations on hip fractures. Eur J Trauma Emerg Surg. 2016;42(4):425-31. doi: https://doi. org/10.1007/s00068-016-0684-3

4. Baixinho CL, Dixe MA, Henriques MAP. Falls in long-term care institutions for elderly people: protocol validation. Rev Bras Enferm. 2017;70(4):740-6. doi: https://doi. org/10.1590/0034-7167-2017-0109

5. Nascimento JS, Tavares DMS. Prevalence and factors associated with falls in the elderly. Texto Contexto Enferm. 2016;25(2):e0360015. doi: https://doi. org/10.1590/0104-07072016000360015

6. Odén A, McCloskey EV, Kanis JA, Harvey NC, Johansson H. Burden of high fracture probability worldwide: secular increases 2010-2040. Osteoporos Int. 2015;26:22438. doi: https://doi.org/10.1007/s00198-015-3154-6

7. Baixinho CL, Dixe MA. Team practices in fall prevention in institutionalized elderly people: scale design and validation. Texto Contexto Enferm. 2017;26(3): e2310016. doi: https://doi.org/10.1590/0104-07072017002310016

8. Marques-Vieira CMA, Sousa LMM, Severino S, Sousa L, Caldeira S. Cross-cultural validation of the falls efficacy scale international in elderly: systematic literature review. J Clin Gerontol Geriatr. 2016;7(3):72-6. doi: https://doi.org/10.1016/j. jcgg.2015.12.002

9. Vitorino LM, Teixeira CAB, Boas ELV, Pereira RL, Santos NO, Rozendo CA. Fear of falling in older adults living at home: associated factors. Rev Esc Enferm USP. 2017;51:e03215. doi: https://doi.org/10.1590/S1980-220X2016223703215

10. Kocic M, Stojanovic Z, Lazovic M, Nikolic D, Zivkovic V, Milenkovic M, et al. Relationship between fear of falling and functional status in nursing home residents aged older than 65 years. Geriatr Gerontol Int. 2017;17(10):1470-6. doi: https://doi.org/10.1111/ggi.12897

11. Corbin J, Strauss A. Basics of qualitative research: techniques and procedures for developing grounded theory. 4th ed. London: Sage Publications; 2014.

12. Oliveira PP, Oliveira AC, Dias AR, Rocha FCV. Caregiver's knowledge about prevention offalls in elderly. Rev Enferm UFPE on line. 2016 [cited 2020 May 12];10(2):58592. Available from: https://periodicos.ufpe.br/revistas/revistaenfermagem/ article/view/10993

13. Shen J, Hu F, Liu F, Tong P. Functional restriction for the fear of falling in family caregivers. Medicine. 2015; 94(27):e1090. doi: https://doi.org/10.1097/ MD.0000000000001090

14. OhE, Hong GS, Lee S, Han S. Fear of falling and its predictors among communityliving older adults in Korea. Aging Ment Health. 2015;21(4):369-78. doi: https:// doi.org/10.1080/13607863.2015.1099034

15. Fitzgerald TG, Hadjistavropoulos T, MacNab YC. Caregiver fear of falling and functional ability among seniors residing in long-term care facilities. Gerontology. 2019;55(4):460-7. doi: https://doi.org/10.1159/000221007

16. Fucahori FS, Lopes AR, Correia JJA, Silva CK, Trelha CS. Fear of falling and activity restriction in older adults from the urban community of Londrina: a cross-sectional study. Fisioter Mov. 2014;27(3):379-87. doi: https://doi.org/10.1590/01035150.027.003.A008 
17. Cameron EJ, Bowles SK, Marshall EG, Andrew MK. Falls and long-term care: a report from the care by design observational cohort study. BMC Fam Pract. 2018;19:73. doi: https://doi.org/10.1186/s12875-018-0741-6

18. Baixinho CL, Dixe MA. Practices and behaviors of professionals after falls in institutionalized elderly with and without cognitive decline. Dement Neuropsychol. 2020;14(1):62-8. doi: https://doi. org/10.1590/1980-57642020dn14-010010

\section{- Authorship contribution:}

Conceptualization - Cristina Lavareda Baixinho, Maria dos Anjos Dixe, Maria Adriana Henriques, Cristina

Marques-Vieira, Luis Sousa.

Data Curation - Cristina Lavareda Baixinho, Maria dos

Anjos Dixe, Maria Adriana Henriques, Cristina MarquesVieira, Luis Sousa.

Formal analysis - Cristina Lavareda Baixinho, Maria dos Anjos Dixe, Maria Adriana Henriques, Cristina Marques-

Vieira, Luis Sousa.

Investigation - Cristina Lavareda Baixinho, Maria dos

Anjos Dixe, Maria Adriana Henriques, Cristina Marques-

Vieira, Luis Sousa.

Methodology - Cristina Lavareda Baixinho, Maria dos

Anjos Dixe, Maria Adriana Henriques, Cristina Marques-

Vieira, Luis Sousa.

Validation - Cristina Lavareda Baixinho, Maria dos Anjos

Dixe, Maria Adriana Henriques, Cristina Marques-Vieira,

Luis Sousa.

Writing - original draft - Cristina Lavareda Baixinho,

Maria dos Anjos Dixe, Maria Adriana Henriques, Cristina

Marques-Vieira, Luis Sousa.

Writing - proofreading and editing - Cristina Lavareda

Baixinho.

\section{- Corresponding author:}

Cristina Lavareda Baixinho

Email: crbaixinho@esel.pt
19. Walker GM, Armstrong S, Gosrdon AL, Gladman J, Robertson K, Ward M, et al. The Falls In Care Home study: a feasibility randomized controlled trial of the use of a risk assessment and decision support tool to prevent falls in care homes. Clin Rehabil. 2016;30(10):972-83. doi: https://doi.org/10.1177/0269215515604672

20. Cunha LFC, Baixinho CL, Henriques MA. Preventing falls in hospitalized elderly: design and validation of a team intervention. Rev Esc Enferm USP. 2019;53:e3479. doi: https://doi.org/10.1590/S1980-220X2018031803479

\section{Associate editor:}

Carlise Rigon Dalla Nora 